\title{
Mitochondria and Alzheimer's Disease: the Role of Mitochondrial Genetic Variation
}

\author{
Perry G. Ridge ${ }^{1} \cdot$ John S. K. Kauwe ${ }^{1}$ \\ Published online: 1 March 2018 \\ (C) The Author(s) 2018. This article is an open access publication
}

\begin{abstract}
Purpose of Review Alzheimer's disease (AD) is the most common form of dementia, affects an increasing number of people worldwide, has a rapidly increasing incidence, and is fatal. In the past several years, significant progress has been made towards solving the genetic architecture of $\mathrm{AD}$, but our understanding remains incomplete and has not led to treatments that either cure or slow disease. There is substantial evidence that mitochondria are involved in AD: mitochondrial functional declines in AD, mitochondrial encoded gene expression changes, mitochondria are morphologically different, and mitochondrial fusion/fission are modified. While a majority of mitochondrial proteins are nuclear encoded and could lead to malfunction in mitochondria, the mitochondrial genome encodes numerous proteins important for the electron transport chain, which if damaged could possibly lead to mitochondrial changes observed in $\mathrm{AD}$. Here, we review publications that describe a relationship between the mitochondrial genome and $\mathrm{AD}$ and make suggestions for analysis approaches and data acquisition, from existing datasets, to study the mitochondrial genetics of AD.

Recent Findings Numerous mitochondrial haplogroups and SNPs have been reported to influence risk for AD, but the majority of these have not been replicated, nor experimentally validated.

Summary The role of the mitochondrial genome in AD remains elusive, and several impediments exist to fully understand the relationship between the mitochondrial genome and $\mathrm{AD}$. Yet, by leveraging existing datasets and implementing appropriate analysis approaches, determining the role of mitochondrial genetics in risk for $\mathrm{AD}$ is possible.
\end{abstract}

Keywords Alzheimer's disease $\cdot$ Mitochondrial genetics $\cdot$ Mitochondrial cascade hypothesis

\section{Introduction}

Alzheimer's disease (AD) is the most common cause of dementia. It affects more than 20 million people worldwide, and the number of cases is expected to continue to increase [1-3]. While recent progress in understanding the genetics of the disease has been encouraging [4-10], there remain no effective strategies for the prevention or cure of $\mathrm{AD}$.

In 2010, Swerdlow et al. [11] proposed the mitochondrial cascade hypothesis of AD. Briefly, an individual's genetics

This article is part of the Topical Collection on Neurogenetics and Psychiatric Genetics

Perry G. Ridge

Perry.Ridge@byu.edu

1 Department of Biology, Brigham Young University, 4102 LSB, Provo, UT 84602, USA determine baseline mitochondrial function and how mitochondria change as a person ages and is exposed to various environmental insults. Declining mitochondrial function then results in AD-specific pathology. This hypothesis receives support from several lines of evidence that suggest an important role of mitochondrial dysfunction in AD. First, mitochondria fundamentally change in a number of ways in AD. The rate of metabolism decreases [12], mitochondrial fusion and fission are disrupted [13], and mitochondrial concentration (i.e., the ratio of mitochondrial genomes to nuclear genomes) decreases in cerebrospinal fluid $[14,15]$. In addition, morphological changes in the mitochondria, such as abnormal sizes and shapes (including both enlarged, very small, and elongated mitochondria [16-18], and reduced numbers of cristae [16]), are observed [11, 19], and enzymes of the electron transport chain encoded in the mitochondrial genome are altered and expression changes [12, 20, 21]. Amyloid plaques are known to aggregate in mitochondria $[22,23]$ and many of the changes noted above take place near amyloid plaques [24]. 
Finally, efficient mitochondrial proteostasis helps offset the effects of aggregating amyloid- $\beta$ [25].

Patterns of inherited risk for $\mathrm{AD}$ also suggest a role for the maternally inherited mitochondria. Individuals with a maternal family history of AD have a higher risk of AD compared to individuals with a paternal family history of $\mathrm{AD}$ (three to nine times higher) $[26,27]$, or no family history, score lower on cognitive tests [28], have a lower age of onset [26, 29], and have more pronounced brain abnormalities consistent with $\mathrm{AD}$ (cerebral metabolic [30], higher $\mathrm{A} \beta$ burden [31], reduction in gray matter volume $[32,33]$, and increased global $\mathrm{PiB}$ uptake PiB-PET [34]). It has also been demonstrated that some of these brain abnormalities are associated with mitochondrial haplotypes [35]. Maternal-specific changes in risk and related $\mathrm{AD}$ phenotypes could be driven by X-linked $\mathrm{AD}$ risk, maternal-specific genetic imprinting, and mitochondrial genetic effects. To our knowledge, there is no published work implicating maternal imprinting or the $\mathrm{X}$ chromosome in $\mathrm{AD}$ risk. Several mitochondrial haplogroups/SNPs (Table 1) have been reported to correlate with $\mathrm{AD}$ [3].

This mitochondrial impact on AD risk could be influenced by several factors. Here, we review what is known about the association of variation in the mitochondrial genome with risk for $\mathrm{AD}$ and comment on methods for increasing the available data for answering this important question.

\section{Mitochondrial Genetics}

Each mitochondrion possesses one or more copies of its own circular genome. The human reference mitochondrial genome (mtDNA) is 16,569 base pairs long and encodes 37 total genes: two ribosomal RNAs, 22 tRNAs, and 13 protein coding genes [54]. Each protein coding gene encodes a component of the electron transport chain, seven from complex 1 (NADH dehydrogenase subunits), three from complex 4 (cytochrome $\mathrm{c}$ oxidase subunits), two from complex 5 (ATP synthase subunits), and 1 from complex 3 (cytochrome b). The majority of mitochondrial proteins, however, are nuclear encoded [55]. While several nuclear-encoded candidate genes have been investigated, the largest and best powered studies of the nuclear genome have failed to identify associations between these genes and risk for $\mathrm{AD}$ [8]. Germline variation in the mtDNA is responsible for numerous neurological diseases (e.g., Leber hereditary optic neuropathy [56], Leigh syndrome [57], neuropathy, ataxia, and retinitis pigmentosa syndrome [58], myoclonic epilepsy with ragged red fibers [59], mitochondrial encephalomyopathy, lactic acidosis, and strokelike episodes [60], etc.) or affects risk (e.g., Parkinson's disease [61]) and are believed to have a pivotal role in aging [62].

Variation in the haploid mitochondrial genome is often described by established haplotype groups. In the mitochondrial phylogenetic tree, major branch points are identified as major mitochondrial haplogroups and are represented by a single letter (e.g., H, V, L, etc.), while mitochondrial subgroups are further defined by additional numbers/letters (e.g., H51A1, L3, etc.) [63]. Clusters are groups of closely related major haplogroups (e.g., HV, UK, etc.). Each mitochondrial haplogroup and subgroup are defined by a specific set of one, or several, mitochondrial SNPs, and each group and haplogroup consists of a number of distinct, but closely related from an evolutionary standpoint, mitochondrial haplotypes [63]. Mitochondrial haplogroups and subgroups identified as associated with $\mathrm{AD}$ could be driven by one or multiple of the SNPs defining the group when using whole mitochondrial genome sequence data. When using limited SNP data, associations could be driven by one or multiple of the SNPs defining the group, or by subgroups that are tagged by those SNPs. Here, we review the mitochondrial clusters, haplogroups, and subgroups reported to affect risk for $\mathrm{AD}$, as well as specific SNPs when reported (summarized in Table 1 and relationships between haplogroups are illustrated in Fig. 1).

\section{Mitochondrial Haplogroups $\mathrm{H}$ and V}

Mitochondrial haplogroup $\mathrm{H}$ and cluster HV, and subgroups, have been implicated in $\mathrm{AD}$ in several published reports. Haplogroup $\mathrm{H}$ was identified as a risk haplotype for $\mathrm{AD}$ [38]. Fesahat et al. used SNPs from the HVS-1 region in the d-loop region of the mtDNA to assign individuals to one of eight different mitochondrial haplogroups. Sixty-two SNPs were genotyped to be able to distinguish between major mitochondrial haplogroups. Five different SNPs were used to identify individuals with an $\mathrm{H}$ haplogroup. Given the relatively small number of queried SNPs, it is not possible to assign individuals to more specific mitochondrial haplogroups. Maruszak et al. [37] likewise reported that haplogroup H increases risk for $\mathrm{AD}$ by sequencing approximately 600 nucleotides of the control region and nine additional coding region SNPs, and comparing frequency in $\mathrm{AD}$ cases and controls. Neither group suggested possible causative SNPs. Coto et al. genotyped seven SNPs to assign individuals to haplogroup $\mathrm{H}$ [39]. While this study was small (discovery and replication datasets totaled 500 cases and 500 controls together), they did include both discovery and replication phases. Of the seven markers they analyzed, just one, m.7028C, had a significant frequency difference between cases and controls.

Cluster $\mathrm{HV}$, which is a combination of haplogroups $\mathrm{H}$ and $\mathrm{V}$, has been reported to be associated with increased risk for AD [36]. Maruszak et al. genotyped 12 mtDNA SNPs from blood (10 SNPs to determine nine different mitochondrial haplogroups, and two functional SNPs). HV was more frequent in cases than controls, even when controlling for APOE $\varepsilon 4$ status, gender, and age of onset. Likewise, Maruszak et al. [37] reported an association between cluster $\mathrm{HV}$ and $\mathrm{AD}$. The authors sequenced about 600 bases of the 
Table 1 Summary of mitochondrial haplogroups, clusters, and SNPs that affect risk for AD

\begin{tabular}{lllll}
\hline Haplogroup/SNP/cluster & Year & Effect & Ethnicity & $\begin{array}{l}\text { Dataset size } \\
\text { (case/control) }\end{array}$
\end{tabular}

Mitochondrial haplogroups $\mathrm{H}$ and $\mathrm{V}$

HV [36]

HV [37]

$\mathrm{H}[38]$

$\mathrm{H}[37]$

H [39]

H5/H5A [40]

H6A1A/H6A1B [41]

Mitochondrial haplogroups $\mathrm{U}$ and $\mathrm{K}$

UK [42]

UK, males only [37]

U, males only [43]

$\mathrm{U}[38]$

U [44]

$\mathrm{U}$, females only [43]

U5B1 or U5B1B2 [45]

U5A1 [37]

K [44]

K [37]

K1A1B or K1A1B2A1 [45]

K1A [37]

Mitochondrial haplogroups $\mathrm{J}$ and $\mathrm{T}$ JT [37]

\section{$\mathrm{J}[46]$}

J1B1 [37]

T, females only [37]

$\mathrm{T}[46]$

Other mitochondrial haplogroups
L1 [47]
B4C1 [48]
B5 [49]
G2A [48]
N9B1 [48]

$\begin{array}{lll}2009 & \text { Risk } & \text { Eastern European } \\ 2011 & \text { Risk } & \text { Eastern European }\end{array}$

$222 / 252$

$422 / 318$

$30 / 100$

2007 Risk $\quad$ Iranian

$422 / 318$

2011 Risk Spanish

2010 Risk Italian

2012 Protective Caucasian

$\begin{array}{lll}2010 & \text { Risk } & \text { Caucasian } \\ 2011 & \text { Protective } & \text { Eastern European } \\ 2004 & \text { Risk } & \begin{array}{c}\text { Unlisted (likely } \\ \text { Caucasian) } \\ \text { Iranian }\end{array} \\ 2007 & \text { Risk } & \\ 2001 & \text { Protective } & \text { Italian } \\ 2004 & \text { Protective } & \text { Unlisted (likely } \\ 2013 & \text { Risk } & \text { Caucasian } \\ 2011 & \text { Protective } & \text { Eastern European } \\ 2001 & \text { Protective } & \text { Italian } \\ 2011 & \text { Protective } & \text { Eastern European } \\ & & \\ 2013 & \text { Risk } & \text { Caucasian } \\ 2011 & \text { Protective } & \text { Eastern European }\end{array}$

$170 / 188$

$422 / 318$

$989 / 328$

$30 / 100$

213/389

$989 / 328$

$154 / 175$

$422 / 318$

213/389

$422 / 318$

$154 / 175$

$422 / 318$

2011 Protective Eastern European

$422 / 318$

2012 Ris
African American and Caucasian

2011 Protective Eastern European

2011 Protective Eastern European

2012 Risk
African American and Caucasian

$\begin{array}{lll}2014 & \text { Risk } & \text { African American } \\ 2009 & \text { Risk } & \text { Japanese } \\ 2015 & \text { Risk } & \text { Han Chinese } \\ 2009 & \text { Risk } & \text { Japanese } \\ 2009 & \text { Risk } & \text { Japanese }\end{array}$

$422 / 318$

$422 / 318$

$3075^{\mathrm{b}}$

$902 / 187^{\mathrm{c}}$

$96 / 96$

$96 / 96$

96/96
12 SNPs

Positions 16024-576 genotyped (whole control region) and 11 additional SNPs

Positions 16024-16383 (HVS-I region) sequenced

Positions 16024-576 (whole control region), 11 additional SNPs

7 SNPs

Positions 16024-576 (whole control region) sequenced

Whole mitochondrial genomes

138 SNPs

Positions 16024-576 (whole control region), 11 additional SNPs

10 SNPs

Positions 16024-16383 (HVS-I region) sequenced

10 restriction sites

10 SNPs

138 SNPs

Positions 16024-576 (whole control region), 11 additional SNPs

10 restriction sites

Positions 16024-576 (whole control region), 11 additional SNPs

138 SNPs

Positions 16024-576 (whole control region), 11 additional SNPs

Positions 16024-576 (whole control region), 11 additional SNPs

$3075^{\mathrm{b}} \quad 138 \mathrm{SNPs}^{\mathrm{b}}$

$341 / 435$ and

$371 / 470^{\mathrm{a}}$
Positions 16024-576 (whole control region), 11 additional SNPs

Positions 16024-576 (whole control region), 11 additional SNPs

$138 \mathrm{SNPs}^{\mathrm{b}}$

138 SNPs

Whole mitochondrial genomes

Control region sequenced and 2 additional SNPs

Whole mitochondrial genomes

Whole mitochondrial genomes 
Table 1 (continued)

\begin{tabular}{|c|c|c|c|c|c|}
\hline Haplogroup/SNP/cluster & Year & Effect & Ethnicity & $\begin{array}{l}\text { Dataset size } \\
\text { (case/control) }\end{array}$ & Dataset type \\
\hline \multicolumn{6}{|l|}{ Other mitochondrial DNA variation } \\
\hline Increased mtDNA rearrangements ${ }^{\mathrm{d}}[50]$ & 2016 & N/A & Unlisted & $13 / 12$ & Whole mitochondrial genomes \\
\hline $\begin{array}{l}\text { mtDNA controls mitochondrial copy } \\
\text { number }^{\mathrm{e}}[51]\end{array}$ & 2014 & N/A & Caucasian & $101 / 632$ & Whole mitochondrial genomes \\
\hline mtDNA deletions ${ }^{\mathrm{f}}[52]$ & 2012 & Risk & Unlisted & $10 / 6$ & RT-PCR of mtDN4 and mtDN1 \\
\hline m.154244A>G [46] & 2012 & Risk & $\begin{array}{l}\text { African American and } \\
\text { Caucasian }\end{array}$ & $3075^{\mathrm{b}}$ & $138 \mathrm{SNPs}^{\mathrm{b}}$ \\
\hline m.14178T>C [46] & 2012 & Risk & $\begin{array}{l}\text { African American and } \\
\text { Caucasian }\end{array}$ & $3075^{\mathrm{b}}$ & $138 \mathrm{SNPs}^{\mathrm{b}}$ \\
\hline
\end{tabular}

${ }^{\mathrm{a}}$ The first set of numbers refers to the discovery dataset, the second to the replication dataset

${ }^{\mathrm{b}}$ All participants were cognitively healthy at the start of the study. The researchers followed study participants for about 10 years, and measured cognition at years 2, 4, and 7 using the Modified Mini-Mental State Examination (3MS) and the Digit Symbol Substitution Test (DSST). One hundred thirty-eight SNPs were used for association analyses and whole mitochondrial genome sequences were acquired for follow-up from 138 study participants

${ }^{\mathrm{c}}$ Study focused on dementia/no dementia, as opposed to $\mathrm{AD} /$ controls

${ }^{\mathrm{d}}$ The authors identified a higher relative proportion of mtDNA rearrangements in the brains of AD patients

${ }^{\mathrm{e}}$ Mitochondrial copy number is reduced in AD. The authors identified two mitochondrial haplogroups, U5A1 and T2, with significantly higher mitochondrial copy numbers compared to all other haplogroups. The authors further identified a possibly functional variant, $\mathrm{m} .9667 \mathrm{~A}>\mathrm{G}$, which could lead to increased expression of TFAM. Increased TFAM has a protective effect in AD. The identified variant could plausibly protect against AD [53]

${ }^{\mathrm{f}}$ The authors observed an increase in mtDNA deletions, which in turn created a cytochrome $\mathrm{C}$ oxidase deficiency in hippocampal cells of AD patients

control region and genotyped nine coding region SNPs to be able to assign individuals to major mitochondrial haplogroups and related subgroups. The authors suggest that $\mathrm{m} .14766 \mathrm{C}>\mathrm{T}$ may be responsible for the observed increase in risk for $\mathrm{AD}$. $\mathrm{m} .14766 \mathrm{C}>\mathrm{T}$ is a nonsynonymous variant located in cytochrome $\mathrm{B}$, which results in a threonine to isoleucine substitution. This is the defining variant for the HV cluster.

Santoro et al. [40] sequenced the d-loop control region and genotyped additional positions in the mtDNA to assign individuals to major haplogroups, and in some cases more specific subgroups. The authors do not report specific positions outside the control region genotyped, but identified 299 mutations in $\mathrm{AD}$ cases outside the control region and 146 mutations in $\mathrm{AD}$ controls outside the control region. In total, they tested $>40$ subgroups and found that individuals with subgroup H5 had increased risk for AD.

Lastly, Ridge et al. [45] identified two subgroups of haplogroup H, H6A1A and H6A1B, that are associated with reduced risk for $\mathrm{AD}$. This was the first study using whole mitochondrial genomic data of which we are aware. The authors used TreeScanning [65] to group evolutionary-related subgroups together for analysis in a haplotype network. The authors considered every clade in the haplotype network with at least five samples. In the clades of interest, there were no $\mathrm{AD}$ cases, only controls. Moreover, the authors pinpointed three single nucleotide mutations likely responsible for the observed correlation $(\mathrm{m} .3915 \mathrm{G}>\mathrm{A}, \mathrm{m} .4727 \mathrm{~A}>\mathrm{G}$, and $\mathrm{m} .9380 \mathrm{G}>\mathrm{A}$ ). All three SNPs are synonymous. The SNPs are located in electron transport genes: NADH dehydrogenase subunit 1 (ND1), NADH dehydrogenase subunit 2 (ND2), and cytochrome $\mathrm{C}$ oxidase subunit 3 (COX3). The use of whole genome sequence data provides additional opportunity for identifying putative functional polymorphisms.

\section{Mitochondrial Haplogroups U and K}

Mitochondrial haplogroups $\mathrm{U}$ and $\mathrm{K}$, and subgroups, have been reported to both increase and decrease risk for $\mathrm{AD}$, with sometimes conflicting reports for a specific haplogroup or cluster. Cluster UK has been reported as both a risk [42] and protective [37] cluster. Lakatos et al. [42] used 138 mitochondrial SNPs genotyped on a SNP array, which are insufficient to definitively define all mitochondrial haplogroups, but are adequate to define large clusters such as UK, and at least some major mitochondrial haplogroups. The authors reported five different SNPs, each of which defines the UK cluster or subgroups of the cluster, as possibly driving the observed association: m.11467A $>\mathrm{G}$ (NADH dehydrogenase subunit 4), m.12308A $>$ G (tRNA leucine 2), m.12372G $>$ A (NADH dehydrogenase subunit 5), m.9698C $>\mathrm{T}$ (cytochrome $\mathrm{C}$ oxidase subunit 3), and m.16270C $>$ T (control region). Since SNP data are incomplete, it is possible, even likely, that identified associations are tagging more specific subgroups of cluster UK. In contrast, Maruszak et al. [37] reported UK as a protective cluster in males. We previously described the data used by Maruszak et al. [37], which included sufficient genotyping to identify haplogroups of interest.

Similar to the UK cluster, haplogroup $U$ has been reported as both a risk [38, 43] and protective [43, 44] haplogroup. Van der Walt et al. [43] genotyped 10 SNPs, 


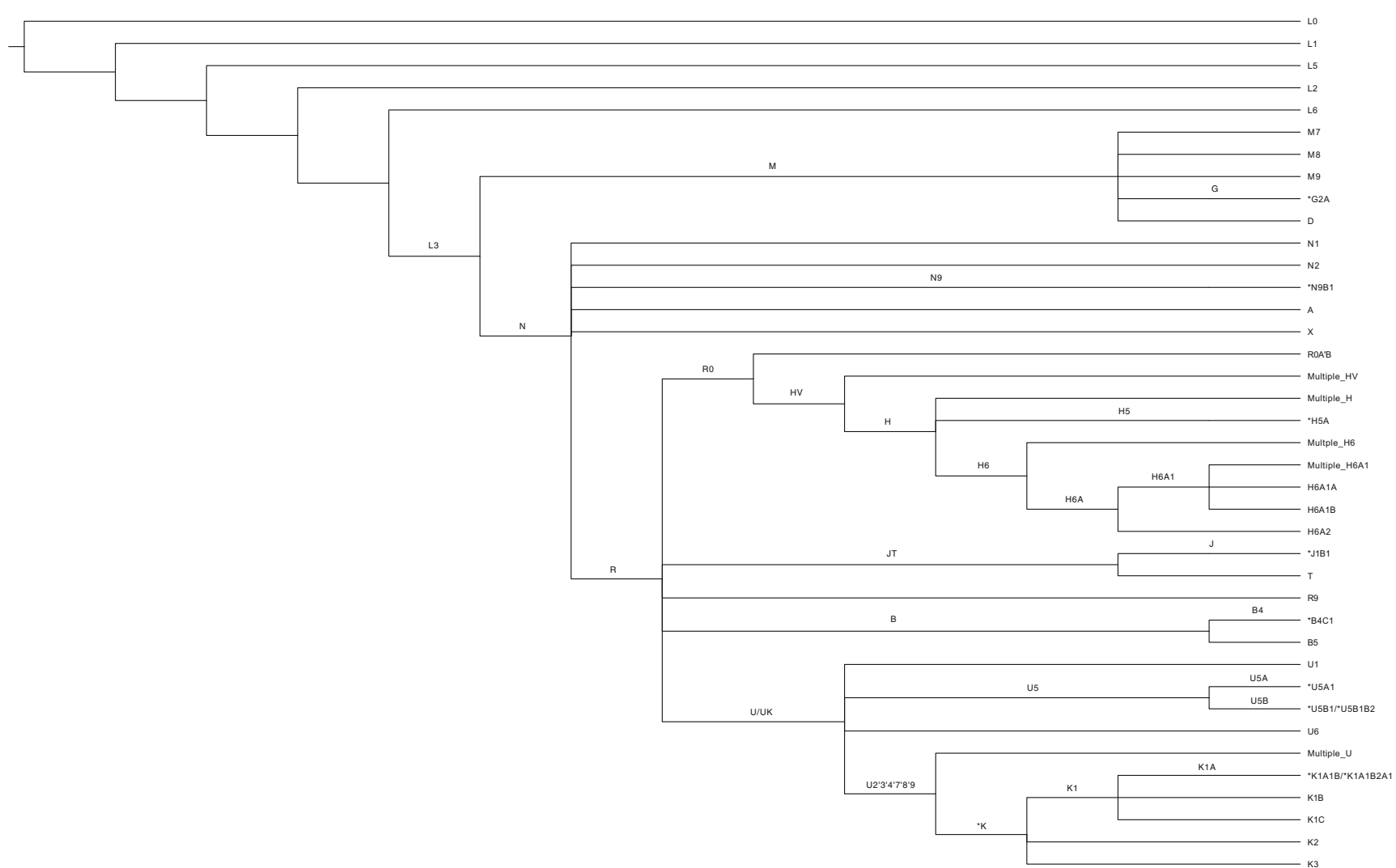

Fig. 1 Mitochondrial network. The network includes all major mitochondrial haplogroups and subgroups described in the manuscript. The root of the tree starts with the hypothetical Mitochondrial Eve. Edges are labeled if they give rise to two or more named haplogroups. For example, $\mathrm{L} 3$ gives rise to haplogroups $\mathrm{M}$ and $\mathrm{N}$. Asterisk indicates that not all branching required to traverse the network to the group is shown. However, in all cases, sufficient branching is included to show the relative relationships between all major haplogroups and subgroups described in the manuscript. Lastly, in several locations, a node label is proceeded by "Multiple_," which indicates that multiple groups have been compressed into a single label. For example, there are numerous H6 subgroups (e.g., H6A, H6B, etc.). However, for the purposes of this manuscript, we are only interested in H6A, so other H6 subgroups are all included in the node labeled Multiple_H6. The relationships between haplogroups are based on Phylotree annotations (Build 17) [64]

Ridge et al. [45] analyzed the relationship between ADspecific physiological changes in the brain and variation in the mitochondrial genome. The authors sought to identify mitochondrial variation associated with 16 different imaging phenotypes and found associations for two different phenotypes (whole brain volume and percent change in temporal pole thickness), possible endophenotypes of AD. The authors used data from the Alzheimer's Disease Neuroimaging Initiative (ADNI) [42] and identified mitochondrial variation associated with increased brain atrophy, consistent with AD. However, as genotypes were available for just 138 mitochondrial SNPs, it was sometimes not possible to assign a specific mitochondrial haplogroup to an individual. In the case of these two associations, available SNPs were only sufficient to assign individuals to two possible haplogroups. The first group consisted of individuals with mitochondrial haplogroup U5B1 or U5B1B2 and the second group K1A1B or K1A1B2A1 (discussed below). In each case, individuals in these groups experienced reductions in temporal pole thickness which would be considered evidence of increased risk for AD. In 
contrast to Ridge et al., Maruszak et al. [37] (dataset described above) reported $\mathrm{U} 5 \mathrm{~A} 1$ as a protective haplogroup.

The $\mathrm{K}$ haplogroup and subgroups have also been reported to increase and reduce risk for AD. In the same two studies just discussed, Ridge et al. [45] reported K1A1B or K1A1B2A1 as risk haplogroups, while Maruszak et al. [37] reported K1A as protective. Maruszak et al. [37] suggests m.497T as a possible functional variant driving the observed protection. m.497T is a control region variant, and it is not clear how it might affect mitochondrial function. Finally, Carrieri et al. [44] and Maruszak et al. [37] both reported that the $\mathrm{K}$ haplogroup reduces risk for $\mathrm{AD}$, and Maruszak et al. [37] suggests that the responsible variants are $\mathrm{m} .9055 \mathrm{G}>\mathrm{A}$ or m.16224C. $\mathrm{m} .9055 \mathrm{G}>\mathrm{A}$ is a nonsynonymous substitution in ATP synthase F0 subunit 6 (ATP6) and results in an alanine to threonine substitution. This substitution has been frequently reported as a possible indicator of longevity [66-68] and as protective against Parkinson's disease [69], which is consistent with a protective role against $\mathrm{AD}$.

\section{Mitochondrial Haplotypes J and T}

Mitochondrial haplogroups $\mathrm{J}$ and $\mathrm{T}$ have been implicated as risk and protective groups. The JT cluster reduces risk in females specifically [37], while individuals with J are more likely to have reduced cognition [47]. Tranah et al. [47] sequenced whole mitochondrial genomes and in parallel genotyped 138 mitochondrial SNPs using a SNP array for each study participant. Individuals with haplogroup J were more likely to experience declines in $3 \mathrm{MS}$ scores. Although the authors sequenced whole mitochondrial genomes, association analyses were only performed on major haplogroups using SNP data from the arrays, so reported results might be tagging subgroups. In contrast, J1B1 appears to have a protective role [37]. J1B1 is defined by m.497T, which is possibly responsible for the observed effect.

The $\mathrm{T}$ haplogroup has been reported to have conflicting roles [37, 47]. In each case, only a sufficient number of mitochondrial SNPs were used to assign individuals to major mitochondrial haplogroups and clusters, although Tranah et al. [47] sequenced the entire mitochondrial genome (they only used 138 SNPs for this particular analysis). It is possible that both are true associations and are tagging different subgroups of T. The association reported by Maruszak et al. [37] is specific to females only.

\section{Other Mitochondrial Haplogroups}

Subgroups of B, G, N, and L have been reported to have a role in $\mathrm{AD} . \mathrm{B} 4 \mathrm{C} 1$ and $\mathrm{B} 5$ are risk groups $[48,49]$. $\mathrm{B} 4 \mathrm{C} 1$ was identified by first selecting Japanese AD patients, identifying the mitochondrial haplogroups possessed by any AD cases, then using a modified neural network (radial basis function) to identify haplogroups of interest. Specific haplogroups were identified by examining differences between $\mathrm{AD}$ cases and healthy Japanese centenarians. Takasaki et al. [48], using the same approach described, also reported that $\mathrm{G} 2 \mathrm{~A}$ and N9B1 increase risk for $\mathrm{AD}$.

Haplogroup B5 was identified by genotyping a sufficient number of SNPs to assign individuals to major mitochondrial haplogroups and a few subgroups and comparing haplogroup frequencies between $\mathrm{AD}$ cases and controls [49]. This is one of the few studies to have attempted replication, and although the association did not replicate, the effect was in the right direction, and when pooling both datasets together, the association reached significance. Finally, the authors experimentally validated their discovery. $\mathrm{m} .8584 \mathrm{G}>\mathrm{A}$ defines $\mathrm{B} 5$ and alters mitochondrial function. In samples carrying this variant, reactive oxygen species (ROS) levels were higher, ATP levels lower, and overall mitochondrial function decreased [49].

Finally, Tranah et al. [46] used 138 mitochondrial SNPs to analyze the relationship between the mitochondrial genome and $\mathrm{AD}$ and dementia in a dataset of African Americans. L1 had increased risk for dementia and lower plasma $A \beta$ levels, while individuals with $\mathrm{L} 3$ had overall higher $\mathrm{A} \beta$ levels.

\section{Conclusions}

A thorough review of mitochondrial genetic discoveries in $\mathrm{AD}$ reveals that there are relatively few definitive findings. For example, numerous studies reported no relationship between mtDNA and AD [70-75], and haplogroups $U$ and T have been reported to both increase and decrease risk for AD. Additionally, to our knowledge, with one exception [39], no identified associations have been replicated and few attempts have been made. A number of issues have likely contributed to our inability to define the relationship between the mitochondrial genome and $\mathrm{AD}$ including small numbers of subjects, insufficient genetic data, and technical challenges in data analysis.

Substantial resources have been committed to developing massive datasets to study the nuclear genetics of AD. For example, the Alzheimer's Disease Sequencing Project (ADSP) [76], Alzheimer's Disease Genetics Consortium (ADGC) [9], and the Alzheimer's Disease Neuroimaging Initiative (ADNI) [77] each have 1000s of samples. Initially, the overwhelming majority were genotyped on SNP arrays, and in the last few years, these efforts have expanded to include exome and whole genome sequencing. In contrast, there are relatively few comparable datasets dedicated to the study of mitochondrial genetics of $\mathrm{AD}$. What datasets exist are typically samples acquired and genotyped by individual researchers. This has resulted in limited numbers of samples with limited genotyping. 
Interestingly, many of the large genetics consortia have actually collected data for the mitochondrial genome in addition to nuclear markers and sequences. Early SNP arrays typically included genotypes for 138 mitochondrial SNPs, while newer arrays include genotypes for 256 mitochondrial SNPs. Hudson et al. leveraged these data from several different datasets and reported no consistent evidence for association with AD [75]. Unfortunately, these SNPs are not sufficient to identify detailed haplogroup and subgroup information for all individuals. This means that unless all subgroups within a haplogroup have a consistent impact on $\mathrm{AD}$, then association cannot be detected. Inconclusive findings in the large sample studied in Hudson et al. [75], for example, may be due to complete lack of association or due to heterogeneity of genetic effects within the haplogroups that were defined in the study subjects.

In this review, we focused on germline variation in the maternally inherited mitochondrial genome. However, it is also possible that somatic mutations appearing in only a few tissues and at relatively low levels compared to the maternally inherited mitochondrial genome (i.e., heteroplasmy) could play a role in AD. Moreover, although the majority of mitochondria are maternally inherited, there is precedent for low levels of paternal mitochondria to escape the selective destruction that is typical and to exist in an individual [78]. Both somatic changes and paternal inheritance of mitochondria could result in varying proportions of mutant mitochondria, which can lead to mitochondrial disease [79]. This might be especially true in the brain, which is sensitive to even subtle changes in energetics. Unfortunately, these are especially difficult to study in the context of AD for two reasons. First, if tissue-specific low levels of mutant mitochondria were responsible for disease, this would require collecting samples of brain tissue. Second, from a technical standpoint, it is difficult to identify rare mutants in a population of mixed cells. Next-generation sequencing (NGS), as described below, might help to overcome this second challenge.

Collection of NGS data provides an important opportunity to expand the study of mitochondrial genetics in AD. While sequenced exomes do not typically include mitochondrial sequence data, whole genome sequence data always includes whole mitochondrial genome sequence data. Raw data from whole genome sequencing represent an untapped resource that could be leveraged to study the mitochondrial genetics of AD. Furthermore, since NGS data rely on redundant sequencing of each base, it may be possible to analyze each read to determine the mix of mutant and wild-type alleles in mitochondria extracted from specific tissues of interest.

Technical impediments exist to using these data. As mitochondrial genomes are haploid, and the majority of algorithms for analyzing genetics data were developed specifically for diploid genomes, many existing approaches for data processing and analysis do not work well for the mitochondrial genome. We recently demonstrated that whole mitochondrial genome sequence data can be used to identify mitochondrial variants [80]. We extracted whole mitochondrial genome data from 805 whole genomes from ADNI. We outlined an approach for accurately determining mitochondrial genotypes from next-generation sequencing data of whole genomes which were $>98 \%$ accurate [80]. Both our methods and the resulting dataset are publically available, with complete mitochondrial genome sequence data, genotypes, and rich phenotypic annotations. This approach could be expanded to additional samples where whole genome sequence data have been collected, resulting in a rich resource for studying the impact of mitochondrial genetic variation on $\mathrm{AD}$ risk.

Approaches to data analysis may also be limiting our discoveries of associations between mitochondrial genetic variation and AD. The majority of studies used only a handful of SNPs, or focused on a few specific mitochondrial haplogroups. Even in cases where whole mitochondrial genomic data have been available, studies have been limited to a small number of markers. This is likely due to the lack of simple approaches for using more detailed genetic data for association studies. Complete sequence of the mitochondrial genome results in high-resolution haplotype data, including many singletons. This results in a large number of subgroups, each with small sample sizes, which leads to significant reductions in statistical power for association testing.

This high-resolution haplotype data can be used to estimate haplotype networks, which represent the evolutionary relationships of the haplotypes. The basic assumption of evolution-based haplotype analyses is that mutations with functional consequences are embedded within the history of the population. Advantages of these methods include the ability to pool haplotypes in meaningful ways to concentrate statistical power on evolutionarily relevant contrasts and detect phenotypically convergent but evolutionarily independent mutations. TreeScanning is a method that incorporates these concepts and a permutation-based multiple test correction to analyze both qualitative and quantitative traits $[65,81,82]$. We have previously used this approach to analyze several genes including DAPK1 [81, 83] and to study the relationship between $\mathrm{AD}$ and the mitochondrial genome [41, 45, 51].

In summary, there is significant evidence for the role of mitochondria in $\mathrm{AD}$ risk. Studies of the contribution of mitochondrial genetic variation to $\mathrm{AD}$ risk remain inconclusive due to small sample sizes, limited genetic data collection, and inadequate approaches to association analysis. Growing sample sizes and the more widespread use of whole genome sequence data in the study of nuclear genetic risk factors for $\mathrm{AD}$ can also be leveraged for the study of mitochondrial genetic variation in $\mathrm{AD}$. The methods and approaches to properly leverage these new data are available and provide a positive outlook for future investigations of mitochondrial genetic contributions to $\mathrm{AD}$ risk. 


\section{Compliance with Ethical Standards}

Conflict of Interest The authors declare that they have no conflict of interest.

Human and Animal Rights and Informed Consent This article does not contain any studies with human or animal subjects performed by any of the authors.

Open Access This article is distributed under the terms of the Creative Commons Attribution 4.0 International License (http:// creativecommons.org/licenses/by/4.0/), which permits unrestricted use, distribution, and reproduction in any medium, provided you give appropriate credit to the original author(s) and the source, provide a link to the Creative Commons license, and indicate if changes were made.

\section{References}

1. Querfurth HW, LaFerla FM. Alzheimer's disease. N Engl J Med. 2010;362(4):329-44. https://doi.org/10.1056/NEJMra0909142.

2. Brookmeyer R, Johnson E, Ziegler-Graham K, Arrighi HM. Forecasting the global burden of Alzheimer's disease. Alzheimers Dement. 2007;3(3):186-91. https://doi.org/10.1016/j.jalz.2007.04. 381.

3. Ridge PG, Ebbert MT, Kauwe JS. Genetics of Alzheimer's disease. Biomed Res Int. 2013;2013:254954.

4. Cruchaga C, Karch CM, Jin SC, Benitez BA, Cai Y, Guerreiro R, et al. Rare coding variants in the phospholipase D3 gene confer risk for Alzheimer's disease. Nature. 2014;505(7484):550-4. https:// doi.org/10.1038/nature12825.

5. Guerreiro R, Wojtas A, Bras J, Carrasquillo M, Rogaeva E, Majounie E, et al. TREM2 variants in Alzheimer's disease. N Engl J Med. 2012;368(2):117-27. https://doi.org/10.1056/ NEJMoa1211851.

6. Hollingworth P, Harold D, Sims R, Gerrish A, Lambert JC, Carrasquillo MM, et al. Common variants at ABCA7, MS4A6A/ MS4A4E, EPHA1, CD33 and CD2AP are associated with Alzheimer's disease. Nat Genet. 2011;43(5):429-35. https://doi. org/10.1038/ng.803.

7. Lambert JC, Heath S, Even G, Campion D, Sleegers K, Hiltunen M, et al. Genome-wide association study identifies variants at CLU and CR1 associated with Alzheimer's disease. Nat Genet. 2009;41(10): 1094-9. https://doi.org/10.1038/ng.439.

8. Lambert JC, Ibrahim-Verbaas CA, Harold D, Naj AC, Sims R, Bellenguez C, et al. Meta-analysis of 74,046 individuals identifies 11 new susceptibility loci for Alzheimer's disease. Nat Genet. 2013;45(12):1452-8. https://doi.org/10.1038/ng.2802.

9. Naj AC, Jun G, Beecham GW, Wang LS, Vardarajan BN, Buros J, et al. Common variants at MS4A4/MS4A6E, CD2AP, CD33 and EPHA1 are associated with late-onset Alzheimer's disease. Nat Genet. 2011;43(5):436-41. https://doi.org/10.1038/ng.801.

10. Ridge PG, Karch CM, Hsu S, Arano I, Teerlink CC, Ebbert MTW, et al. Linkage, whole genome sequence, and biological data implicate variants in RAB10 in Alzheimer's disease resilience. Genome Med. 2017;9(1):100. https://doi.org/10.1186/s13073-017-0486-1.

11. Swerdlow RH, Burns JM, Khan SM. The Alzheimer's disease mitochondrial cascade hypothesis. J Alzheimers Dis. 2010;20(Suppl 2):S265-79. https://doi.org/10.3233/JAD-2010-100339.

12. Santos RX, Correia SC, Wang X, Perry G, Smith MA, Moreira PI, et al. Alzheimer's disease: diverse aspects of mitochondrial malfunctioning. Int J Clin Exp Pathol. 2010;3(6):570-81.
13. Cunnane S, Nugent S, Roy M, Courchesne-Loyer A, Croteau E, Tremblay S, et al. Brain fuel metabolism, aging, and Alzheimer's disease. Nutrition. 2011;27(1):3-20. https://doi.org/10.1016/j.nut. 2010.07.021.

14. Wang X, Su B, Lee HG, Li X, Perry G, Smith MA, et al. Impaired balance of mitochondrial fission and fusion in Alzheimer's disease. J Neurosci. 2009;29(28):9090-103. https://doi.org/10.1523/ JNEUROSCI.1357-09.2009.

15. Podlesniy P, Llorens F, Golanska E, Sikorska B, Liberski P, Zerr I, et al. Mitochondrial DNA differentiates Alzheimer's disease from Creutzfeldt-Jakob disease. Alzheimers Dement. 2016;12(5):54655. https://doi.org/10.1016/j.jalz.2015.12.011.

16. Trimmer PA, Swerdlow RH, Parks JK, Keeney P, Bennett JP Jr, Miller SW, et al. Abnormal mitochondrial morphology in sporadic Parkinson's and Alzheimer's disease cybrid cell lines. Exp Neurol. 2000;162(1):37-50. https://doi.org/10.1006/exnr.2000.7333.

17. Baloyannis SJ. Mitochondrial alterations in Alzheimer's disease. J Alzheimers Dis. 2006;9(2):119-26. https://doi.org/10.3233/JAD2006-9204.

18. Bonda DJ, Smith MA, Perry G, Lee HG, Wang X, Zhu X. The mitochondrial dynamics of Alzheimer's disease and Parkinson's disease offer important opportunities for therapeutic intervention. Curr Pharm Des. 2011;17(31):3374-80. https://doi.org/10.2174/ 138161211798072562.

19. Podlesniy P, Figueiro-Silva J, Llado A, Antonell A, Sanchez-Valle $\mathrm{R}$, Alcolea D, et al. Low cerebrospinal fluid concentration of mitochondrial DNA in preclinical Alzheimer disease. Ann Neurol. 2013;74(5):655-68. https://doi.org/10.1002/ana.23955.

20. Chan DC. Mitochondria: dynamic organelles in disease, aging, and development. Cell. 2006;125(7):1241-52. https://doi.org/10.1016/ j.cell.2006.06.010.

21. Lunnon K, Keohane A, Pidsley R, Newhouse S, Riddoch-Contreras $\mathrm{J}$, Thubron EB, et al. Mitochondrial genes are altered in blood early in Alzheimer's disease. Neurobiol Aging. 2017;53:36-47. https:// doi.org/10.1016/j.neurobiolaging.2016.12.029.

22. Du H, Guo L, Yan S, Sosunov AA, McKhann GM, Yan SS. Early deficits in synaptic mitochondria in an Alzheimer's disease mouse model. Proc Natl Acad Sci U S A. 2010;107(43):18670-5. https:// doi.org/10.1073/pnas.1006586107.

23. Anandatheerthavarada HK, Devi L. Amyloid precursor protein and mitochondrial dysfunction in Alzheimer's disease. Neuroscientist. 2007;13(6):626-38. https://doi.org/10.1177/1073858407303536.

24. Devi L, Prabhu BM, Galati DF, Avadhani NG, Anandatheerthavarada HK. Accumulation of amyloid precursor protein in the mitochondrial import channels of human Alzheimer's disease brain is associated with mitochondrial dysfunction. J Neurosci. 2006;26(35):9057-68. https://doi.org/10. 1523/JNEUROSCI.1469-06.2006.

25. Sorrentino V, Romani M, Mouchiroud L, Beck JS, Zhang H, D'Amico D, et al. Enhancing mitochondrial proteostasis reduces amyloid-beta proteotoxicity. Nature. 2017;552(7684):187-93. https://doi.org/10.1038/nature25143.

26. Xie H, Guan J, Borrelli LA, Xu J, Serrano-Pozo A, Bacskai BJ. Mitochondrial alterations near amyloid plaques in an Alzheimer's disease mouse model. J Neurosci. 2013;33(43):17042-51. https:// doi.org/10.1523/JNEUROSCI.1836-13.2013.

27. Gomez-Tortosa E, Barquero MS, Baron M, Sainz MJ, Manzano S, Payno M, et al. Variability of age at onset in siblings with familial Alzheimer disease. Arch Neurol. 2007;64(12):1743-8. https://doi. org/10.1001/archneur.64.12.1743.

28. Edland SD, Silverman JM, Peskind ER, Tsuang D, Wijsman E, Morris JC. Increased risk of dementia in mothers of Alzheimer's disease cases: evidence for maternal inheritance. Neurology. 1996;47(1):254-6. https://doi.org/10.1212/WNL.47.1.254.

29. Seshadri S, Wolf PA, Beiser A, Au R, McNulty K, White R, et al. Lifetime risk of dementia and Alzheimer's disease. The impact of 
mortality on risk estimates in the Framingham study. Neurology. 1997;49(6):1498-504. https://doi.org/10.1212/WNL.49.6.1498.

30. Duara R, Barker WW, Lopez-Alberola R, Loewenstein DA, Grau LB, Gilchrist D, et al. Alzheimer's disease: interaction of apolipoprotein E genotype, family history of dementia, gender, education, ethnicity, and age of onset. Neurology. 1996;46(6):1575-9. https:// doi.org/10.1212/WNL.46.6.1575.

31. Mosconi L, Mistur R, Switalski R, Brys M, Glodzik L, Rich K, et al. Declining brain glucose metabolism in normal individuals with a maternal history of Alzheimer disease. Neurology. 2009;72(6):513-20. https://doi.org/10.1212/01.wnl.0000333247. 51383.43.

32. Mosconi L, Rinne JO, Tsui WH, Berti V, Li Y, Wang H, et al. Increased fibrillar amyloid-\{beta $\}$ burden in normal individuals with a family history of late-onset Alzheimer's. Proc Natl Acad Sci U S A. 2010;107(13):5949-54. https://doi.org/10.1073/pnas. 0914141107.

33. Honea RA, Swerdlow RH, Vidoni ED, Goodwin J, Burns JM. Reduced gray matter volume in normal adults with a maternal family history of Alzheimer disease. Neurology. 2010;74(2):113-20. https://doi.org/10.1212/WNL.0b013e3181c918cb.

34. Honea RA, Swerdlow RH, Vidoni ED, Burns JM. Progressive regional atrophy in normal adults with a maternal history of Alzheimer disease. Neurology. 2011;76(9):822-9. https://doi.org/ 10.1212/WNL.0b013e31820e7b74.

35. Honea RA, Vidoni ED, Swerdlow RH, Burns JM. Maternal family history is associated with Alzheimer's disease biomarkers. J Alzheimers Dis. 2012;31(3):659-68. https://doi.org/10.3233/JAD2012-120676.

36. Maruszak A, Canter JA, Styczynska M, Zekanowski C, Barcikowska M. Mitochondrial haplogroup H and Alzheimer's disease - is there a connection? Neurobiol Aging. 2009;30(11): 1749-55. https://doi.org/10.1016/j.neurobiolaging.2008.01.004.

37. Maruszak A, Safranow K, Branicki W, Gaweda-Walerych K, Pospiech E, Gabryelewicz T, et al. The impact of mitochondrial and nuclear DNA variants on late-onset Alzheimer's disease risk. J Alzheimers Dis. 2011;27(1):197-210. https://doi.org/10.3233/ JAD-2011-110710.

38. Fesahat F, Houshmand M, Panahi MS, Gharagozli K, Mirzajani F. Do haplogroups $\mathrm{H}$ and $\mathrm{U}$ act to increase the penetrance of Alzheimer's disease? Cell Mol Neurobiol. 2007;27(3):329-34. https://doi.org/10.1007/s10571-006-9126-9.

39. Coto E, Gomez J, Alonso B, Corao AI, Diaz M, Menendez M, et al. Late-onset Alzheimer's disease is associated with mitochondrial DNA 7028C/haplogroup H and D310 poly-C tract heteroplasmy. Neurogenetics. 2011;12(4):345-6. https://doi.org/10.1007/s10048011-0295-4.

40. Santoro A, Balbi V, Balducci E, Pirazzini C, Rosini F, Tavano F, et al. Evidence for sub-haplogroup h5 of mitochondrial DNA as a risk factor for late onset Alzheimer's disease. PLoS One. 2010;5(8): e12037. https://doi.org/10.1371/journal.pone.0012037.

41. Ridge PG, Maxwell TJ, Corcoran CD, Norton MC, Tschanz JT, O'Brien E, et al. Mitochondrial genomic analysis of late onset Alzheimer's disease reveals protective haplogroups H6A1A/ H6A1B: the Cache County Study on Memory in Aging. PLoS One. 2012;7(9):e45134. https://doi.org/10.1371/journal.pone. 0045134.

42. Lakatos A, Derbeneva O, Younes D, Keator D, Bakken T, Lvova $\mathrm{M}$, et al. Association between mitochondrial DNA variations and Alzheimer's disease in the ADNI cohort. Neurobiol Aging. 2010;31(8):1355-63. https://doi.org/10.1016/j.neurobiolaging. 2010.04.031

43. van der Walt JM, Dementieva YA, Martin ER, Scott WK, Nicodemus KK, Kroner CC, et al. Analysis of European mitochondrial haplogroups with Alzheimer disease risk. Neurosci Lett. 2004;365(1):28-32. https://doi.org/10.1016/j.neulet.2004.04.051.
44. Carrieri G, Bonafe M, De Luca M, Rose G, Varcasia O, Bruni A, et al. Mitochondrial DNA haplogroups and APOE4 allele are nonindependent variables in sporadic Alzheimer's disease. Hum Genet. 2001;108(3):194-8. https://doi.org/10.1007/s004390100463.

45. Ridge PG, Koop A, Maxwell TJ, Bailey MH, Swerdlow RH, Kauwe JS, et al. Mitochondrial haplotypes associated with biomarkers for Alzheimer's disease. PLoS One. 2013;8(9):e74158. https://doi.org/10.1371/journal.pone.0074158.

46. Tranah GJ, Nalls MA, Katzman SM, Yokoyama JS, Lam ET, Zhao $\mathrm{Y}$, et al. Mitochondrial DNA sequence variation associated with dementia and cognitive function in the elderly. J Alzheimers Dis. 2012;32(2):357-72. https://doi.org/10.3233/JAD-2012-120466.

47. Tranah GJ, Yokoyama JS, Katzman SM, Nalls MA, Newman AB, Harris TB, et al. Mitochondrial DNA sequence associations with dementia and amyloid-beta in elderly African Americans. Neurobiol Aging. 2014;35(2):442 e1-8. https://doi.org/10.1016/j. neurobiolaging.2013.05.023.

48. Takasaki S. Mitochondrial haplogroups associated with Japanese Alzheimer's patients. J Bioenerg Biomembr. 2009;41(5):407-10. https://doi.org/10.1007/s10863-009-9240-8.

49. Bi R, Zhang W, Yu D, Li X, Wang HZ, Hu QX, et al. Mitochondrial DNA haplogroup B5 confers genetic susceptibility to Alzheimer's disease in Han Chinese. Neurobiol Aging. 2015;36(3):1604 e7-16. https://doi.org/10.1016/j.neurobiolaging.2014.10.009.

50. Chen Y, Liu C, Parker WD, Chen H, Beach TG, Liu X, et al. Mitochondrial DNA rearrangement spectrum in brain tissue of Alzheimer's disease: analysis of 13 cases. PLoS One. 2016;11(6): e0154582. https://doi.org/10.1371/journal.pone.0154582.

51. Ridge PG, Maxwell TJ, Foutz SJ, Bailey MH, Corcoran CD, Tschanz JT, et al. Mitochondrial genomic variation associated with higher mitochondrial copy number: the Cache County Study on Memory Health and Aging. BMC Bioinformatics. 2014;15(Suppl 7):S6.

52. Krishnan KJ, Ratnaike TE, De Gruyter HL, Jaros E, Turnbull DM. Mitochondrial DNA deletions cause the biochemical defect observed in Alzheimer's disease. Neurobiol Aging. 2012;33(9): 2210-4. https://doi.org/10.1016/j.neurobiolaging.2011.08.009.

53. Oka S, Leon J, Sakumi K, Ide T, Kang D, LaFerla FM, et al. Human mitochondrial transcriptional factor A breaks the mitochondriamediated vicious cycle in Alzheimer's disease. Sci Rep. 2016;6(1):37889. https://doi.org/10.1038/srep37889.

54. Iborra FJ, Kimura H, Cook PR. The functional organization of mitochondrial genomes in human cells. BMC Biol. 2004;2(1):9. https://doi.org/10.1186/1741-7007-2-9.

55. Chacinska A, Koehler CM, Milenkovic D, Lithgow T, Pfanner N. Importing mitochondrial proteins: machineries and mechanisms. Cell. 2009;138(4):628-44. https://doi.org/10.1016/j.cell.2009.08. 005 .

56. Yu-Wai-Man P, Griffiths PG, Hudson G, Chinnery PF. Inherited mitochondrial optic neuropathies. J Med Genet. 2009;46(3):14558. https://doi.org/10.1136/jmg.2007.054270.

57. DiMauro S, Schon EA. Mitochondrial respiratory-chain diseases. N Engl J Med. 2003;348(26):2656-68. https://doi.org/10.1056/ NEJMra022567.

58. Thorburn DR, Rahman J, Rahman S. Mitochondrial DNAassociated Leigh syndrome and NARP. In: Adam MP, Ardinger HH, Pagon RA, Wallace SE, Bean LJH, Mefford HC, et al., editors. GeneReviews(R). Seattle; 1993.

59. Shoffner JM, Wallace DC. Mitochondrial genetics: principles and practice. Am J Hum Genet. 1992;51(6):1179-86.

60. Tranchant C, Anheim M. Movement disorders in mitochondrial diseases. Rev Neurol (Paris). 2016;172(8-9):524-9. https://doi. org/10.1016/j.neurol.2016.07.003.

61. Winklhofer KF, Haass C. Mitochondrial dysfunction in Parkinson's disease. Biochim Biophys Acta. 2010;1802(1):29-44. https://doi. org/10.1016/j.bbadis.2009.08.013. 
62. Sun N, Youle RJ, Finkel T. The mitochondrial basis of aging. Mol Cell. 2016;61(5):654-66. https://doi.org/10.1016/j.molcel.2016.01. 028.

63. Mitchell SL, Goodloe R, Brown-Gentry K, Pendergrass SA, Murdock DG, Crawford DC. Characterization of mitochondrial haplogroups in a large population-based sample from the United States. Hum Genet. 2014;133(7):861-8. https://doi.org/10.1007/ s00439-014-1421-9.

64. van Oven M, Kayser M. Updated comprehensive phylogenetic tree of global human mitochondrial DNA variation. Hum Mutat. 2009;30(2):E386-94. https://doi.org/10.1002/humu.20921.

65. Templeton AR, Maxwell T, Posada D, Stengard JH, Boerwinkle E, Sing CF. Tree scanning: a method for using haplotype trees in phenotype/genotype association studies. Genetics. 2005;169(1): 441-53. https://doi.org/10.1534/genetics.104.030080.

66. Ross OA, McCormack R, Curran MD, Duguid RA, Barnett YA, Rea IM, et al. Mitochondrial DNA polymorphism: its role in longevity of the Irish population. Exp Gerontol. 2001;36(7):1161-78. https://doi.org/10.1016/S0531-5565(01)00094-8.

67. Ivanova R, Lepage V, Charron D, Schachter F. Mitochondrial genotype associated with French Caucasian centenarians. Gerontology. 1998;44(6):349. https://doi.org/10.1159/000022041.

68. Niemi AK, Hervonen A, Hurme M, Karhunen PJ, Jylha M, Majamaa K. Mitochondrial DNA polymorphisms associated with longevity in a Finnish population. Hum Genet. 2003;112(1):29-33. https://doi.org/10.1007/s00439-002-0843-y.

69. van der Walt JM, Nicodemus KK, Martin ER, Scott WK, Nance MA, Watts RL, et al. Mitochondrial polymorphisms significantly reduce the risk of Parkinson disease. Am J Hum Genet. 2003;72(4): 804-11. https://doi.org/10.1086/373937.

70. Zsurka G, Kalman J, Csaszar A, Rasko I, Janka Z, Venetianer P. No mitochondrial haplotype was found to increase risk for Alzheimer's disease. Biol Psychiatry. 1998;44(5):371-3. https://doi.org/10. 1016/S0006-3223(97)00461-7.

71. Chinnery PF, Taylor GA, Howell N, Andrews RM, Morris CM, Taylor RW, et al. Mitochondrial DNA haplogroups and susceptibility to AD and dementia with Lewy bodies. Neurology. 2000;55(2): 302-4. https://doi.org/10.1212/WNL.55.2.302.

72. Pyle A, Foltynie T, Tiangyou W, Lambert C, Keers SM, Allcock LM, et al. Mitochondrial DNA haplogroup cluster UKJT reduces the risk of PD. Ann Neurol. 2005;57(4):564-7. https://doi.org/10. 1002/ana.20417.
73. Mancuso M, Nardini M, Micheli D, Rocchi A, Nesti C, Giglioli NJ, et al. Lack of association between mtDNA haplogroups and Alzheimer's disease in Tuscany. Neurol Sci. 2007;28(3):142-7. https://doi.org/10.1007/s10072-007-0807-z.

74. Kruger J, Hinttala R, Majamaa K, Remes AM. Mitochondrial DNA haplogroups in early-onset Alzheimer's disease and frontotemporal lobar degeneration. Mol Neurodegener. 2010;5(1):8. https://doi. org/10.1186/1750-1326-5-8.

75. Hudson G, Sims R, Harold D, Chapman J, Hollingworth P, Gerrish A, et al. No consistent evidence for association between mtDNA variants and Alzheimer disease. Neurology. 2012;78(14):1038-42. https://doi.org/10.1212/WNL.0b013e31824e8fld.

76. Project AsDS. Alzheimer's Disease Sequencing Project. 2016.

77. Mueller SG, Weiner MW, Thal LJ, Petersen RC, Jack CR, Jagust W, et al. Ways toward an early diagnosis in Alzheimer's disease: the Alzheimer's Disease Neuroimaging Initiative (ADNI). Alzheimers Dement. 2005;1(1):55-66. https://doi.org/10.1016/j.jalz.2005.06. 003.

78. Schwartz M, Vissing J. Paternal inheritance of mitochondrial DNA. N Engl J Med. 2002;347(8):576-80. https://doi.org/10.1056/ NEJMoa020350.

79. Stewart JB, Chinnery PF. The dynamics of mitochondrial DNA heteroplasmy: implications for human health and disease. Nat Rev Genet. 2015;16(9):530-42. https://doi.org/10.1038/nrg3966.

80. Ridge PG, Wadsworth ME, Miller JB, Saykin AJ, Green RC, ADNI, et al. Assembly of 809 whole mitochondrial genomes with clinical, imaging, and fluid biomarker phenotyping. Alzheimers Demen. 2017; Accepted.

81. Grupe A, Li Y, Rowland C, Nowotny P, Hinrichs AL, Smemo S, et al. A scan of chromosome 10 identifies a novel locus showing strong association with late-onset Alzheimer disease. Am J Hum Genet. 2006;78(1):78-88. https://doi.org/10.1086/498851.

82. Posada D, Maxwell TJ, Templeton AR. TreeScan: a bioinformatic application to search for genotype/phenotype associations using haplotype trees. Bioinformatics. 2005;21(9):2130-2. https://doi. org/10.1093/bioinformatics/bti293.

83. Li Y, Grupe A, Rowland C, Nowotny P, Kauwe JS, Smemo S, et al. DAPK1 variants are associated with Alzheimer's disease and allelespecific expression. Hum Mol Genet. 2006;15(17):2560-8. https:// doi.org/10.1093/hmg/ddl178. 